\title{
The Partnership in Teacher Excellence Program: A District-University Collaboration to Create Teacher Leaders
}

\author{
Nathan Bond ${ }^{1,}$, Marilyn Goodwin ${ }^{1} \&$ Emily Summers ${ }^{1}$ \\ ${ }^{1}$ Department of Curriculum \& Instruction, Texas State University - San Marcos, San Marcos, USA \\ *Department of Curriculum \& Instruction, Texas State University - San Marcos, San Marcos, USA \\ E-mail: NathanBond@txstate.edu
}

Received: January 23, 2013 Accepted: April 8, $2013 \quad$ Online Published: April 29, 2013

doi:10.5430/jct.v2n1p91 URL: http://dx.doi.org/10.5430/jct.v2n1p91

\begin{abstract}
This article describes the conditions for establishing an advanced master's degree program that focuses on teacher leadership. The creation of the model is examined from the perspective of nine administrators from Eanes Independent School District in Austin, Texas, and Texas State University - San Marcos. These administrators collaborated to design the Partnership in Teacher Excellence Program (PTEP), with the purpose of developing teacher leaders who would become experts in their subject areas, deliver high-quality classroom instruction to their K-12 students, provide ongoing professional development to their colleagues in the district, and serve in a variety of teacher leadership roles. Emerging from anecdotal evidence are positive results that confirm the administrators' efforts to develop PTEP.
\end{abstract}

Keywords: teacher leadership; model; graduate degree

With more pressure to increase student learning and improve the overall quality of $\mathrm{K}-12$ schools, administrators at these levels are considering teacher leadership as a way to empower faculty and bring about positive meaningful change on their campuses. Administrators acknowledge that teachers are already leaders of the children in their classrooms (Schelty, 2000); however, they need teachers to assume additional responsibilities beyond the classroom and to serve in leadership roles with their peers (Danielson, 2007). Teachers can serve as leaders in informal ways by mentoring colleagues and supporting instructional programs and in formal ways by serving as instructional leaders and lead teachers (Zepeda, Mayers, \& Benson, 2003). Modern schools have become complex and difficult for principals to run singlehandedly (Lambert, 2003). Administrators must deal with issues such as public pressure for accountability, diminishing resources for serving students, uneven parental and community support, increased time demands, and a general lack of respect for the teaching profession (Usdan, McCloud, \& Podmostko, 2001).

A responsibility teacher leaders might assume is to provide colleagues with job-embedded, ongoing professional development. Educational scholars note a direct correlation here: When teachers enhance their content and pedagogical knowledge, students learn more (Darling-Hammond, Wei, Andree, Richardson, \& Orphanos, 2009). Teacher leaders are ideal candidates to facilitate professional development since they stay current with the latest trends in their subject areas and are credible sources of knowledge in their colleagues' eyes. The world's twenty-five best-performing school systems follow this model and regularly rely on in-service teachers to "coach other teachers, enter classrooms to observe teachers, give feedback, model instruction, and share in planning" (Barber \& Mourshed, 2007, p. 29).

This article describes the conditions that led school district and university administrators to establish an advanced master's degree program that focuses on teacher leadership. Administrators from Eanes Independent School District (Eanes ISD) in Austin, Texas, and Texas State University - San Marcos collaborated to design the Partnership in Teacher Excellence Program (PTEP) with the purpose of developing teacher leaders who would become experts in their subject areas; deliver high-quality classroom instruction to their $\mathrm{K}-12$ students; provide ongoing professional development to their colleagues in the district; and serve in a variety of teacher leadership roles, such as instructional coaches, team leaders, and department chairs. The development of the model is examined from the perspective of four district administrators and five university administrators. Positive results emerging from anecdotal evidence 
confirm the administrators' decisions to develop PTEP.

\section{Unique Features of PTEP}

Several features made PTEP unique: (a) the master's degree focused on the classroom-level aspects of teacher leadership; (b) the suburban school district was continually labeled exemplary or high performing, based on student performance on state-mandated assessments; (c) the district formally supported ongoing professional development through a policy that required all newly hired teachers to obtain a master's degree within the first six years of employment; (d) the Eanes Education Foundation, a philanthropic group of district residents, provided scholarships to offset costs for tuition and books; (e) the university and the district co-constructed the curriculum to meet the teachers' specific needs; and (f) the university adapted its course delivery to meet the teachers' needs, including teaching the graduate classes onsite in the district and providing individual mentoring for the required teacher research projects.

\section{Relevant Scholarship}

In 2004, York-Barr and Duke reviewed two decades of research and discovered seven programs that focused on the development of teacher leaders. Three themes emerged from these researchers' analyses. Teacher leaders must (1) continuously learn about and demonstrate advanced curricular, instructional, and assessment practices; (2) demonstrate an understanding of school culture and ways to initiate and support change in schools; and (3) develop the knowledge and skills necessary to support the development of colleagues in individual, small group, and large group interactions.

Building on York-Barr and Duke's work, we conducted a literature review of empirical studies that concentrated on the three key descriptors related to our study: teacher leadership, university-district partnerships, and master's degree programs. Only one study (Henning, Trent, Engelbrecht, Robinson, \& Reed, 2004) resembled ours by meeting all three criteria. These researchers examined a graduate degree program in teacher leadership that brought together educators from the University of Northern Iowa with those in a local, urban school district. The program's overarching goals were to close the achievement gap between various ethnic groups and recruit new leadership in the district. Graduating teacher leaders were prepared to facilitate professional learning communities, engage peers in analyses of student work, and collect and interpret action research data. The university secured grant funds to establish the partnership, offset tuition costs, and provide participants with release time from teaching. Organized by cohorts, the participants moved through a series of modules based on four principles: job-embedded tasks, collaboration, inquiry, and standards. This study differed from ours in several important ways: all participants in their study taught in low socio-economic schools with diverse student populations, the graduates were allowed to leave the classroom in order to become administrators, and grant money was used to start and sustain the program.

We identified three studies that focused on teacher leadership and university-district partnerships but did not result in a master's degree (Chartrand, Moore, \& Lourie-Markowitz, 2000; Crawford, Roberts, \& Hickman, 2008; Gemo, Meskel, \& Rieckhoff, 2009). An analysis of these studies revealed some commonalities. The goals of the partnerships were to improve the quality of teaching and increase student learning in the schools. To accomplish these goals the partnerships encouraged teachers to assume an inquiry stance by reflecting on and questioning the effectiveness of their instruction and to collaborate regularly with other teachers in the school. Finally, all teachers eventually assumed leadership roles on their campuses.

Although the goals were the same, these partnerships took different pathways to prepare the teacher leaders. For example, faculty at a university in northern California developed a series of professional development workshops to prepare teacher leaders in two local school districts (Chartrand, Moore, \& Lourie-Markowitz, 2000). This multi-pronged approach provided differentiated training on leadership to teachers based on their years of classroom experience. Novices received a review of lesson planning while experienced educators received more advanced information on leadership, long-term planning, and literacy instruction.

Professors in Florida worked closely with classroom teachers in a local private school system with grades K-8 to build a professional development program that lasted three years (Crawford, Roberts, \& Hickman, 2008). Teachers at all career stages studied the best practices for teaching their grade level during the first year of the program, writing across the curriculum during the second, and implementing teacher leadership and educational change during the third. Unlike the approach mentioned in the previous paragraph, teacher leadership was taught as a topic at the end rather than as a theme woven throughout all three years. 
Finally, professors at DePaul University in Illinois developed a teacher leadership program in a professional development school operated by teachers in a local Catholic elementary school (Gemo, Meskel, \& Rieckhoff, 2009). In-service teachers developed their leadership skills by mentoring beginning teachers and collaborating with colleagues to complete school-based curricular projects. By following this approach, teacher leadership emerged organically through the completion of school-related activities.

We included in our review of literature four related studies that describe graduate programs in teacher leadership that were not affiliated with university partnerships (Hambright \& Franco, 2008; Ovington, Diamantes, \& Roby, 2002; Ross, Adams, Bondy, Dana, Dodman, \& Swain, 2011; Valli, van Zee, Rennert-Ariev, Mikeska, Catlett-Muhammad, \& Roy, 2006). Although these studies are only somewhat related, they still offer useful information.

An analysis of these programs revealed some similarities. First, they all offered courses that helped teachers to improve their instruction and become teacher leaders. The courses focused on research, curriculum development, student assessment, and educational change. Next, the programs were founded on guiding principles that included inquiry, reflection, and collaboration. Teachers learned how to question events in the classroom and school and work with others to formulate systematic approaches for finding solutions. Lastly, the professors at these institutions were able to assess the impact of their programs. Graduates reported an increased feeling of confidence, greater effectiveness in the classroom, and a desire to serve in leadership roles in the schools.

Despite these similarities, the studies differed significantly. Ovington, Diamontes, and Roby (2002) and Hambright and Franco (2008) described the well-established graduate program in teacher leadership at Wright State University. The program's curriculum closely resembled one that was used to prepare administrators. Both programs required students to complete a series of leadership courses. They differed in the location where the courses were offered, the method of instructional delivery, and the rate at which the graduate students matriculated through the program.

Ross, Adams, Bondy, Dana, Dodman, and Swain (2011) conducted a longitudinal study of their own master's degree program at the University of Florida and found that graduates were "transformed" as classroom teacher leaders. In other words, transformed teachers viewed themselves as being more professional in their attitudes toward and interactions with others. Principals confirmed the graduates' self-assessments. The teacher leaders in the program learned how to develop an inquiry stance toward their teaching, collaborate with others, cultivate professional learning communities, write grants, and analyze data from assessments administered to students.

Inquiry played a significant role in the graduate program on teacher leadership at the University of Maryland, College Park (Valli, van Zee, Rennert-Ariev, Mikeska, Catlett-Muhammad, \& Roy, 2006). These researchers found that initiating and sustaining a culture of inquiry by conducting action research studies empowered participants to become teacher leaders. As in the studies mentioned above, the program had a positive impact on its students. By questioning what they did, participants carefully examined their teaching practice, teacher leadership decisions, and student learning.

\section{Method}

\subsection{Overview of PTEP}

Established in 2006, PTEP is open to teachers at all grade levels and in all subject areas within Eanes ISD. Cohorts of five to fifteen in number take graduate courses over a two-year period on both the university campus and on school sites in the district. Teachers complete the 36-hour program with majors in elementary education, secondary education, or special education. Teachers also select a minor from the areas of gifted and talented education, educational technology, educational administration, or a specific subject area, such as English Language Arts or Mathematics. Providing choice in the minor allows the participants to tailor the program to fit their needs while satisfying one of PTEP's goals, which is to help teachers to become experts in their subject areas.

As part of the requirements of PTEP, all teachers take leadership, research, and pedagogy courses that prepare them to serve in a leadership capacity. The teacher leadership course examines ways to lead in the classroom, school, district, and community. Mentoring, peer coaching, and professional learning communities are a few of the topics that are studied. Three educational research courses equip teachers with the tools to design and implement an action research study in their schools and write a scholarly paper for publication or presentation. To achieve these high expectations, teachers receive ongoing support from the PTEP professors.

\subsection{The Partners}

Eanes ISD is a mid-sized suburban district that borders a large metropolitan area in the Southwest. The district serves 
more than 7,300 students in its six elementary schools, two middle schools, and one high school. According to the demographic data collected by the state's education agency, $83 \%$ of the students are Caucasian, $9 \%$ are Asian/Pacific Islander, 7\% are Hispanic, and 1\% are African American and Native American (Texas Education Agency, 2012). Three percent of the students are considered economically disadvantaged. The academic reputation of the district is strong. In 2012, all nine schools received the highest rating of exemplary on the state's accountability measure.

Texas State University - San Marcos is a large comprehensive university with an enrollment of more than 34,000 students. Founded in 1899 primarily as a teacher college, the institution has expanded its mission over the years to become a multipurpose university with nine colleges and more than 200 undergraduate and graduate degrees. The Carnegie Foundation places Texas State University - San Marcos in the category of Emerging Research Institution. Data show that approximately 1,500 students are enrolled in the master's and doctoral programs in the College of Education. Partnerships between the university and local districts have been an integral and consistent part of the college's history. In the 1990s as the professional development school movement was becoming more accepted (Holmes Group, 1986), the university began partnering with more than 30 local schools to prepare pre-service teachers. Now it collaborates with schools across the state to prepare pre-service teachers and provide professional development to in-service teachers.

\subsection{Data Collection and Analysis}

The data collected for this qualitative case study came from individual, face-to-face interviews with four administrators in Eanes ISD and five administrators at Texas State University - San Marcos. The interviews followed a semi-structured format, lasted an hour, and were recorded and transcribed by the researchers, who are also the authors of this manuscript. The questions sought information about the program's origin, goals, barriers, strengths, and areas for improvement. In addition, questions explored how the district and university were recruiting teachers to participate in the program, supporting them during the program, and utilizing them upon graduation from the program. The researchers asked these questions in order to gain insights into the administrators' decisions and actions for creating this model to prepare teacher leaders. The ultimate goal of the paper is to provide an explanation of the model for developing teacher leaders.

To ensure trustworthiness, the researchers conducted member checks with each participant and worked independently, employing the constant comparative method of data analysis to identify emerging themes (Glaser \& Strauss, 1967). After completing their preliminary analyses independently, the researchers came together to discuss their initial coding, refine their analyses, and reach consensus on the themes.

The participants were purposely chosen because of their direct role in creating the advanced master's degree program (Yin, 2003). The administrators from Eanes ISD included the Superintendent, the Assistant Superintendent for Curriculum and Instruction, the Assistant Superintendent for Human Resources, and the district's PTEP Coordinator, who also served as the Assistant Principal at one of the elementary schools. The administrators from the College of Education at Texas State University - San Marcos included the Dean, the Associate Dean for Academic Affairs, the Assistant Dean for Academic Affairs, the Co-Director of the Office of Educator Preparation, and the Chair of the Department of Curriculum and Instruction.

\section{Findings}

This study attempts to explain the conditions that led school district and university administrators to establish an advanced master's degree program that focuses on teacher leadership. Three themes emerged from the analysis of the interview data. First, the administrators described how the master's degree program aligned with their vision for their respective school district or university. Second, they discussed the roles that they wanted the teacher leaders to assume upon graduation. Third, they began to identify the resources and support they would need to provide for the program to succeed. In the following sections, we explain the findings from our study and weave in corresponding published research.

\subsection{Alignment to the District's Vision}

Two groups in Eanes ISD played instrumental roles in the creation of PTEP. The first group included parents in the district who wanted to provide funds for a special project to benefit their children's teachers. The parents did not want the money to go to the district's general operation accounts, booster clubs, or parent-teacher associations, all of which were already supported through property taxes and private donations.

The second group, consisting of the Superintendent and her administrative leadership team, merged their vision and 
knowledge of the district with the parents' request. Since the superintendent is considered the executive leader of the school district, she ultimately sets the tone and the vision for the future (Kowalski, 2006; Wells, Maxfield, Klocko, \& Feun, 2010). Developing a shared vision or a mental image of what an individual and an organization value is important because the common goal leads to "binding norms of behavior" (Harris \& Muijs, 2004, p. 52). Individuals are motivated by their own goals as well as those of the organization.

When asked about the genesis of PTEP, the Superintendent explained how the program fit well with the components of her vision for the district. She explained:

Teachers are our point of touch, they are our delivery. The relationship between a teacher and a student is what we do, so the better that we strengthen the relationship, the better the quality of teaching and the more students will learn.

Teacher quality and student achievement are closely related. When skilled teachers deliver engaging lessons, students learn (Darling-Hammond \& Youngs, 2002). Superintendents often initiate the efforts to improve the quality of teaching in the district. In her study of superintendents' perceptions of teacher leadership, Wells (2012) found that superintendents are frequently "responsible for leading changes that center on scholastic improvements of students and the growth of best educational practice of teachers" (p. 3).

Next, the Superintendent believed that teachers are responsible for helping not only students but colleagues as well. She stated:

When you look at other professions, for example, you have doctors. They don't work in isolation. They consult. They have to. I hope that when I am sick, my doctor is consulting, talking, and debating the best protocol for my treatment. Teachers should do the very same.

Collaboration is essential to a teacher leader's work. In an advice book for teacher leaders, Gabriel (2005) wrote, "Collaborators evolve into learning partners, equally invested in each other and in improving achievement" (p. 110). Moreover, the Superintendent wanted the teachers to embrace the idea of life-long learning. She elaborated her reasoning:

This community values higher education. If your son or daughter is going to Harvard or Yale, obviously you think higher education is an important component. And don't you wish that the teacher they have is well educated and well prepared so that the students can take that next step?

In other words, the Superintendent believed that if students were to matriculate to prestigious universities, they needed teachers who possess deep levels of knowledge. Steel and Craig (2006) reported:

A school administrator must be able to recognize the limitations or gaps in teachers' content and pedagogical knowledge and must foster an atmosphere in which growth in these areas becomes a priority... No one is expected to have mastered instructional techniques on the first day of the classroom. Instead, everyone is expected to be adding to his or her skills consistently over time (p. 679).

Utilizing the parents' funds to support the attainment of advanced degrees seemed logical. The district rejected the idea of performance pay because it was controversial and difficult to measure. Degrees from university were a more quantifiable way to measure instructional quality. Also, the district's school board had recently passed a policy requiring all newly hired teachers to earn a master's degree within their first six years of employment. This decision reflected the institutional support that is necessary for the success of a teacher leadership program (Bishop, Tinley, \& Berman, 1997). The researchers concluded that "since policies usually guide the actions of a substantial portion of the total organization, teachers will believe that they are empowered when they feel that their actions are undergirded and protected by such formalized policy statements" (p. 78).

\subsection{Alignment to the University's Vision}

Eanes ISD approached Texas State University - San Marcos about forming a partnership that would result in the district's teachers earning advanced master's degrees and becoming teacher leaders. The Dean of the College of Education and her administrative leadership team merged the district's request with their own vision and knowledge of the university, summarizing two points of her vision for the college. First, the university must serve its neighboring districts, whether through preparing pre-service teachers or providing professional development to in-service teachers. Simply stated, the university has a responsibility to utilize its resources to improve the quality of instruction for teachers at all stages of their careers.

Second, she believed in creating innovative two-way partnerships with school districts. She envisioned "a different type of partnership, one that was formative in nature and responsive to the needs of both partners." In a formative 
partnership, both parties would benefit from the two institutions working together. The university would gain access to high-quality supervisors for its student teachers as well as feedback on their performance, both of which would help the university to improve the overall quality of its work. On the other side, the district would benefit because participating teachers would have an opportunity through advanced coursework to "hone, sharpen, and focus their teaching skills." The college hoped that, after developing this model, it could be replicated with other districts in the region.

Like the administrators in Eanes ISD, the Dean and her administrative team conducted an environmental scan to determine the views of the university's stakeholders. At the time, the federal government was encouraging universities to create formative partnerships and wanted to award grants to institutions that focused on professional development and teacher quality. In addition, the state government was beginning to hold colleges of education responsible for the quality of their graduates. The last stakeholder, the university itself, wanted the college to increase enrollments in its graduate programs.

The Dean and her administrators took the necessary steps, which aligned well with current research on successful university-district partnerships. By seeking input from and working closely with the various stakeholders, she established a culture that emphasized improved teacher preparation and a shared commitment to innovative practice (Maier \& Bump, 2011).

\subsection{Roles Identified by the District for the New Teacher Leaders}

Preliminary discussions helped the district and university administrators to understand the goals of the program and the roles the teacher leaders would eventually assume. Specifically, the district wanted the graduates to remain in the classroom and become experts in their subject areas. For graduates who worked at the secondary level, they would teach dual credit courses for students seeking high school and college credit. The district was not interested in having the teacher leaders become principals. Unlike some districts around the state with top-heavy leadership structures, Eanes ISD had few administrators and wished to remain that way. However, to prepare for the influx of teacher leaders, the district began creating new teacher leadership positions for graduates to occupy at the class, grade, and campus levels.

The district called the new positions "instructional partners," which are the same as what are commonly known in the literature as "instructional coaches." The Assistant Superintendent for Curriculum and Instruction explained why renaming the position was important:

We are emphasizing the partnership piece. We have really high quality teachers in the district and didn't want any of them thinking that they needed a coach, but you do need a partner to support you and help you to find resources.

While some teacher leaders would become instructional partners, others would serve in more tradition leadership roles, such as instructional specialists, team leaders, department chairs, or members of campus-level decision-making committees. Still others would serve as mentors helping with the induction of beginning teachers. These teacher leadership roles aligned well with the recommendations from scholars (Barth, 2001; Katzenmeyer \& Moller, 2001; Zepeda, Mayers, \& Benson, 2003).

Delivering high-quality professional development on their campuses was a specific role that Eanes ISD wanted the new teacher leaders to assume. The Superintendent stated:

When we need topics to be taught, we will have a pool of teachers who have just gone through the current research today and can form a bridge between professional environments. They're ready to share with their colleagues. They will have the credibility; they will have the skills. All they need is the opportunity.

Relying on teacher leaders to provide the professional development would be advantageous because principals would not be required to maintain expertise in all areas of instruction. They could delegate the responsibility of professional developer to a teacher leader. In a survey examining teacher leadership roles, Dozier (2007) found that "Ninety-three percent have conducted professional development sessions for colleagues; $83 \%$ have engaged in curriculum development; $84 \%$ have served as department chairs, team leaders, or grade-level chairs; and $84 \%$ have mentored new teachers" (p. 54).

\subsection{Roles Identified by the University for the New Teacher Leaders}

The Dean of the College of Education identified some ways that the graduates from PTEP could help with the university's teacher preparation program:

They are trying to follow the "trainers of trainers" model. These cohorts will become teachers of other teachers, coaching and mentoring, especially of the new teachers. We would utilize them if they returned to the university as 
faculty and taught classes like the university seminar. They are a talent pool for us to utilize.

Discussing the rationale for school-university partnerships when the idea was relatively new to the profession, Goodlad (1988) argued, "Successful partnerships are symbiotic relationships. That is, they are joined intimately in mutually beneficial relationships" (p. 14). University-district partnerships can be win-win situations.

\subsection{Support from the District for the Teacher Leaders in PTEP}

The school district and the university supported the teachers in PTEP in a variety of different ways, all of which were succinctly captured in the Superintendent's remark, "Time and money." The Eanes Education Foundation provided scholarship money that paid half of each teacher's tuition. The district believed that only half of the tuition should be paid because, as the Superintendent noted, "We wanted them to have some skin in the game."

The district also provided additional resources. The Eanes Education Foundation gave each teacher a textbook stipend to supplement the tuition scholarship. When asked why the foundation was willing to give the extra money, the Superintendent replied:

[Donating money for specific reasons] gives the donors a purpose. It's easy to say, "I want to contribute to teachers." But, this was quantifiable. This was something you could say, "Well, I put money into the fund to pay for the books for teachers who are working on their master's." That is very satisfying for the donors.

The teachers also received travel money to present their research at conferences. These funds helped pay for the airfare, hotel accommodations, and conference registration, and provided a substitute in the teacher's absence. The Assistant Superintendent for Human Resources stated:

If we have a teacher who has completed a body of work to be published, either in some type of journal or magazine, or if they are presenting their findings at a conference, we would offer support, again financial, but also moral support as well, to compensate them for their travel.

Financial support to attend conferences is integral to a program's success because teacher leaders need time to interact and share their findings with fellow professionals (Kelehear \& Davison, 2005).

Recognizing this point, the district gave the teachers the necessary time. When teachers presented at conferences, their absences did not count against their number of sick or personal days. When they needed time to prepare for their final exams and participate in their graduation ceremonies, the district also awarded them two personal days. Researchers (i.e., Katzenmeyer \& Moller, 2001; Rogers, 2005; Salsberry \& Wetig, 2004) have identified time as a critical factor in helping teacher leaders to complete their extra responsibilities. Ovando (1996) determined, "Teachers mostly performed their leadership tasks during planning periods, regular conference periods, lunch periods, professional days, release time, and before and after school" (p. 37). The researcher concluded that squeezing leadership duties into the day negatively affected the quality of teacher leader's performance.

Furthermore, other requirements were amended to support the participants in PTEP. Qualified teachers were allowed to choose an alternative appraisal system in lieu of the state-mandated evaluation. The alternative system required the teachers to meet individually with their administrator, discuss their annual professional goals, and explain their action research project and its impact on student learning in the classroom. The district's PTEP Coordinator commented:

I think that [the new appraisal system] has really helped open the door for those types of conversations with the administrators because some of them, prior to that, were not even aware that their teachers were doing research.... It's nice for them [the teacher leaders] if they have an alternative for their evaluation process that is a part of what they're already doing. It's not an additional piece of work that they have to do.

Finally, Eanes ISD provided tangible and intangible forms of assistance. Teachers with young children paid a discounted rate for the district-managed child care facility. Each teacher received a laptop to use, with the option of purchasing it upon graduation. Finally, each teacher was assisted by a program coordinator who managed the day-to-day operations from the district's side of the partnership and provided assistance when teachers applied for admission to the university and for scholarships from the foundation.

\subsection{Support from the University for the Teacher Leaders in PTEP}

The university provided support to the teachers during PTEP. The Department Chair from Curriculum and Instruction allocated dedicated professors to teach in the program. She remarked, "We chose our top professors to teach in the program. That's number one. [They are] our best teachers and researchers." Echoing ideas on the importance of the faculty, the Co-director of the Office of Teacher Preparation reiterated: 
Faculty members have been designated specifically to this program, providing stability to the program and the ability to establish relationships with these cohort members. Knowing the faculty involved, I know that they provide guidance, advice, and consultation to these students both during their time in the program as well as afterwards.

In a paper on effective graduate programs, Blackwell and Diez (1998) claimed, "Faculty involvement and commitment are key aspects of a quality master's program. Components of faculty commitment are an active interest in the students in the program and a willingness to devote time to student issues" (p. 15).

The university held the graduate classes on various campuses in the district, an effective and relatively easy way to help the teacher leaders. The Assistant Superintendent for Human Resources stated:

When you have professors coming to us, that is a support for our teachers not having to drive, even though it's only 30 miles to [University's Name], which is really helpful if you have some young moms with kids who want this, but sometimes the day care and timing doesn't work out for them.

The university also provided travel money for the professors who did not live in or near the district.

Like the district, the university appointed a coordinator to manage its side of the program. The Department Chair of Curriculum and Instruction explained:

We've provided a coordinator for the program who is also their personal graduate advisor who does their degree plans, consults with them on their coursework, and just takes care of the paperwork and helps them navigate the [University's Name] system.

Blackwell and Diez (1998) argued, "A critical mass of committed faculty, with at least one faculty member who is willing to serve as leader and advocate, is essential for the health of a master's program that will maintain the other criteria [for success] we identify" (p. 15).

After completing the program, the teachers received additional support. As graduates, they gained access to a large alumni network and received opportunities to teach at the university level. The Dean shared some of her preliminary ideas for using the graduates when she said, "I'm hoping that we can also utilize them as model teachers and use them in our preparation program for pre-service teachers." It was part of the Dean's job description to engage alumni in the events of the college and honor them for their outstanding teaching during formal recognition ceremonies.

\section{Conclusion}

This article has outlined the conditions that led nine administrators to create PTEP, an advanced master's degree program that harnessed the strengths of a high-performing school district and an outreach-oriented university. The administrators' goals for the program included developing teacher leaders who could provide exemplary instruction to students in the classroom and meaningful professional development to colleagues in the school. The study found that the administrators' visions for their respective schools played an important role in the development of the program. Two additional key findings showed that all stakeholders must clearly understand the teacher leadership roles that will be available after graduation and that sufficient support is required for the teacher leaders throughout the program.

Building on previous studies about collaborative master's degree programs, this study adds significant information to the current discussion on teacher leadership. Existing published studies, as cited in the review of literature, propose good models and some suggestions for the development of such graduate programs. The model by Henning, Trent, Engelbrecht, Robinson, and Reed (2004) closely resembled our study. These researchers were successful increasing "the pool of available leadership" in the partnering school district (p. 414). Preliminary results showed that teacher leaders in the program were closing the achievement gap among various student populations and facilitating professional learning communities. Unlike these researchers' investigation, our study did not focus on K-12 student achievement. It did, however, show that graduates were beginning to facilitate professional development for colleagues. Our study goes further and provides important details and raises key issues that should be considered by administrators who are interested in replicating the model on their campuses.

Schools, for example, should consider ways to support teachers while they are seeking advanced degrees. They may need to offer scholarships and other financial incentives to assist teachers during tight budgetary times. They may also need to give teachers more time or more flexibility with their time to pursue the degree. Likewise, universities who seek partnerships with districts may want to consider ways to make the collaborations more viable to teacher participants. Offering courses within the district and designing creative curricula are effective strategies that require little money. 
Although the study yielded important conclusions, it is not without its criticisms. Specifically, it was conducted under fairly ideal conditions. Eanes ISD is a high-performing district with a supportive community, and Texas State University - San Marcos has a proven record of partnering with local school districts. Both have knowledgeable, forward-thinking administrators who are willing to try innovative approaches to solve challenging problems. Studies conducted under these conditions are important because they confirm what is possible. The next step is to conduct additional studies to determine if the model can be replicated successfully when some conditions are altered. For example, would the model work in a district that is identified as low-performing? Would it work if the university were less willing to deliver courses off campus? Perhaps the most important question that needs to be investigated is: Does the program yield improved $\mathrm{K}-12$ student learning?

Once PTEP was firmly established, school and university administrators began conducting formative assessments to evaluate the effectiveness of the program. The preliminary findings are positive and will appear in future research articles. A few noteworthy outcomes include the development of sustainable professional learning communities by the teacher leaders who graduated from the program. Principals report that the teacher leaders are taking the initiative to facilitate professional development for colleagues in their respective schools. In addition, almost half of the teacher leaders are publishing their action research papers in scholarly journals and presenting at educational conferences. These teacher leaders are serving as ambassadors from the district to the larger professional community and sharing their expertise. The findings from our study suggest that meaningful partnerships between school districts and universities can be designed to foster teacher leadership.

\section{Acknowledgement}

The authors would like to thank Kathleen Magor for her insightful feedback on this manuscript.

\section{References}

Barber, M., \& Mourshed, M. (2007). How the world's best-performing school systems come out on top. London: McKinsey. http://dx.doi.org/10.1007/s10833-011-9175-9

Barth, R. (2001). Teacher leader. Phi Delta Kappan, 82(6), 443-449. http://dx.doi.org/10.2307/20439932

Bishop, H. L., Tinley, A., \& Berman, B. T. (1997). A contemporary leadership model to promote teacher leadership. Action in Teacher Education, 19(3), 77-81.

Blackwell, P. J., \& Diez, M. (1998). Toward a new vision of master's education for teachers. Washington, DC: National Council for Accreditation of Teacher Education.

Chartrand, G., Moore, C., \& Lourie-Markowitz, N. (2000). Teacher training for lifelong learning and leadership. Thrust for Educational Leadership, 29(3), 22-25.

Crawford, P. A., Roberts, S. K., \& Hickman, R. (2008). All together now: Authentic university-school partnerships for professional development. Childhood Education, 85(2), 91-95.

Danielson, C. (2007). The many faces of leadership. Educational Leadership, 65(1), 14-19.

Darling-Hammond, L., Wei, R. C., Andree, A., Richardson, N., \& Orphanos, S. (2009). State of the profession. Journal of Staff Development, 30(2), 42-50.

Darling-Hammond, L., \& Youngs, P. (2002). Defining 'highly qualified teachers': What does 'scientifically-based research tells us? Education Researcher, 31(9), 13-25. http://dx.doi.org/10.3102/0013189X031009013

Dozier, T. K. (2007). Turning good teachers into great leaders. Educational Leadership, 65(1), 54-58.

Gabriel, J. G. (2005). How to thrive as a teacher leader. Alexandria, VA: Association for Supervision and Curriculum Development.

Gemo, R., Meskel, N., \& Rieckhoff, B. (2009). Increasing teacher leadership through university and school collaboration. Momentum, 40(1), 32-35.

Glaser, B. G., \& Strauss, A. L. (1967). The discovery of grounded theory: Strategies for qualitative research. Chicago: Aldine Publishing Company.

Goodlad, J. (1988). School-university partnership for educational research: Rationale and concepts. In K. A. Sirotnik and J. Goodlad (Eds.), School-university partnerships in action: Concepts, cases, and concerns (pp. 32-66). 
New York: Teachers College Press.

Hambright, W. G., \& Franco, M. S. (2008). Living the "tipping point": Concurrent teacher leader and principal preparation. Education, 129(2), 267-273.

Harris, A., \& Muijs, D. (2004). Improving schools through teacher leadership. Berkshire, Great Britain: Open University Press.

Henning, J. E., Trent, V., Engelbrecht, D., Robinson, V., \& Reed, G. A. (2004). Cultivating teacher leadership through a school and university partnership. Teacher Education and Practice, 17(4), 400-416.

Holmes Group (1986). Tomorrow's teacher: A report of the Holmes Group. East Lansing, MI: The Holmes Group.

Katzenmeyer, M., \& Moller, G. (2001). Awakening the sleeping giant: Helping teachers develop as leaders. Thousand Oaks, CA: Corwin Press.

Kelehear, Z., \& Davison, G. (2005). Teacher teams step up to leadership. Journal of Staff Development, 26(3), 54-59.

Kowalski, T. J. (2006). The school superintendent: Theory, practice, and cases. Thousand Oaks, CA: Sage Publications.

Lambert, L. (2003). Leadership capacity for lasting school improvement. Alexandria, VA: Association for Supervision and Curriculum Development.

Maier, J. N., \& Bump, W. M. (2011). Better schools - better teachers: An analysis of a professional development school's internship program using the National Association of Professional Development School's nine essentials. In J. L. Nath, I. N. Guadarrama, \& J. Ramsy (Eds.), Investigating university-school partnerships (pp. 29-47). Greenwich, CT: Information Age Publishing.

Ovando, M. N. (1996). Teacher leadership: Opportunities and challenges. Planning and Changing, 27(1), 30-44.

Ovington, J. A., Diamantes, T., \& Roby, D. A. (2002). An early distance learning success story: The teacher leadership program. College Student Journal, 36(3), 387-398.

Rogers, J. (2005). Aspiring to leadership: Identifying teacher leaders. Medical Teacher, 27(7), 629-633.

Ross, D., Adams, A., Bondy, E., Dana, N., Dodman, S., \& Swain, C. (2011). Preparing teacher leaders: Perceptions of the impact of a cohort-based, job embedded, blended teacher leadership program. Teaching and Teacher Education, 27, 1213-1222. http://dx.doi.org/10.1016/j.tate.2011.06.005

Salsberry T., \& Wetig, S. (2004). Clinical instructors as teacher leaders in the professional development schools: Benefits, challenges, and support systems. Delta Kappa Gamma Bulletin, 71(1), 36-55.

Schlechty, P. C. (2000). Leading a school system through change. In M. Fullan (Ed.), The Jossey-Bass reader on educational leadership (pp. 182-201). Chicago: Jossey-Bass.

Steel, C., \& Craig, E. (2006). Reworking industrial models, exploring contemporary ideas, and fostering teacher leadership. Phi Delta Kappan, 87(9), 676-680.

Texas Education Agency. (2012). 2008-09 Academic Excellence Indicator System (AEIS) state, district, and campus reports. Austin, Texas: Author. Retrieved from http://ritter.tea.state.tx.us/perfreport/aeis/

Usdan, M., McCloud, B., \& Podmostko, M. (2001). Leadership for student learning: Redefining the teacher as leader. Washington, DC: Institute for Educational Leadership.

Valli, L., van Zee, E. H., Rennert-Ariev, P., Mikeska, J. Catlett-Mohammad, S., \& Roy, P. (2006). Initiating and sustaining a culture of inquiry in a teacher leadership program. Teacher Education Quarterly, 33(3), 97-114.

Yin, R. K. (2003). Case study research: Design and methods. Thousand Oaks, CA: Sage.

York-Barr, J., \& Duke, K. (2004). What do we know about teacher leadership? Findings from two decades of scholarship. Review of Educational Research, 74(3), 255-316. http://dx.doi.org/10.2307/3516026

Wells, C. M. (2012). Superintendents' perceptions of teacher leadership in selected districts. International Journal of Educational Leadership Preparation, 7(2), 1-10.

Wells, C. M., Maxfield, C. R., Klocko, B., \& Feun, L. (2010). The role of superintendents in supporting teacher leadership: A study of principals' perceptions. Journal of School Leadership, 20(5), 669-693.

Zepeda, S. J., Mayers, R. S., \& Benson, B. N. (2003). Call to teacher leadership. Larchmont, NY: Eye on Education. 